\title{
Differential mobility spectrometry-mass spectrometry (DMS-MS) for Uranium Ion Prefiltration to Improve Isotope Ratio Analysis.
}

\author{
Ifeoluwa Ayodeji ${ }^{1}$, Nelson Perdomo ${ }^{1}$, Jacob Shelley ${ }^{2}$, and Theresa Evans-Nguyen ${ }^{*}$ \\ ${ }^{1}$ University of South Florida, Tampa, FL 33620 \\ ${ }^{2}$ Department of Chemistry and Chemical Biology, Rensselaer Polytechnic Institute, Troy, NY 12180
}

\begin{abstract}
The characterization of uranium and other radionuclides is an important topic of sustained interest because they generate high-yield power with low greenhouse gas emissions. Conversely, uncontrolled proliferation of these materials and associated fission fragments could be life-threatening. Conventionally, isotope-ratio mass spectrometry (IRMS) is typically employed as a lab-based system for quantification and characterization of isotope ratios (IR). Unfortunately, size, weight and power (SWaP) requirements make it undesirable for in-situ applications. Further, laborious sample processing and longanalysis times make it less amenable for real-time detection and identification. Additionally, the risk associated with transporting nuclear material from the field to the laboratory is a major concern. Differential mobility spectrometry (DMS) has been a promising analytical technique for field sampling, filtration, and analysis of target analytes from their native state on the order of milliseconds. With the heterogeneous nature of radionuclides and fission products, employing DMS filtration prior to MS analysis removes chemical interferences, while ions of interest can be selectively characterized. Herein, DMS was coupled to a linear ion trap mass spectrometer for pre-filtration of the uranyl ion $\left(\mathrm{UO}_{2}^{+}\right)$from chemical background produced from nano electrospray ionization. Subsequently, isotopic analysis was conducted on the uranyl ion. The ${ }^{235} \mathrm{U} /{ }^{238} \mathrm{U}$ ratio measured with DMS-MS hyphenated system shows improved signal to noise ( $\mathrm{S} / \mathrm{N}$ ) ratio, as opposed to $\mathrm{MS}$ as a standalone system. This improved result indicates that DMS can be potentially coupled to the IRMS for improve confidence of nuclear isotope assay result, specified by International Target Values (ITVs).
\end{abstract}

\section{INTRODUCTION}

Uranium and other nuclear materials among other energy sources, remains a vital topic because they generate high-yield power ${ }^{1}$ with low greenhouse gas emission. ${ }^{2}$ Unfortunately, uncontrolled proliferation of these materials could be life-threatening. ${ }^{3,4}$ Despite the obvious benefits of nuclear power, public perception and acceptance is a major concern following various accidents. ${ }^{5,6}$ International regulation such as the Nuclear Nonproliferation Treaty (NPT) adopted protocols for safeguards measuring techniques for accountability of uranium $(\mathrm{U})$ and plutonium $(\mathrm{Pu})$ only. ${ }^{7}$ While $\mathrm{U}$ and $\mathrm{Pu}$ are the big players, other radionuclides, stable fragments and heavy metals also pose a great risk to human life and environment. For instance, the byproducts of nuclear fission, such as ${ }^{137} \mathrm{Cs},{ }^{90} \mathrm{Sr}\left(\mathrm{t}_{1} / 2 \approx 30\right.$ years $),{ }^{8}$ are not only highly radioactive but can be environmentally persistent. While conventional handheld devices, like a GeigerMüller probe can detect radiation events in real time, stable fragments which could be a radiation precursor in the near future cannot be detected. ${ }^{9}$ Furthermore, a Geiger-Mueller meter does not provide 
identifying information on the radionuclide being detected. As a result, there is a need for the development of a rapid and high-throughput analytical sensor that can selectively detect radionuclides and associated fission products from various sources including nuclear power or reprocessing plants, decommissioned sites, and post-detonation scenes.

Mass spectrometry (MS) stands out among other analytical techniques due to its sensitivity and isotopic selectivity, which is unmatched. As such, MS-based methods are the "state-of-the-art" method for nuclear forensic analyses. ${ }^{10-14}$ Individual isotopes of atomic species are identified and quantified with a high level of precision and accuracy. The International Atomic Energy Agency (IAEA) established International Target Values (ITVs) to ascertain confidence of results and reliability specific to various isotopic assays. For instance, the level of isotope-ratio accuracy and precision required for MS-based methods (thermalionization MS and inductively coupled plasma-MS) is based on ${ }^{235} \mathrm{U}$ isotopic abundance (cf. Table 1). ${ }^{15}$

Table 1. Classification of Uranium based on isotope ${ }^{235}$ U composition

\begin{tabular}{|c|c|}
\hline Uranium Class & ${ }^{235} \mathbf{U}$ Composition (\%) \\
\hline Depleted U & $<0.3 \%{ }^{235} \mathrm{U}$ \\
\hline Natural $U$ & $0.3 \%<<^{235} \mathrm{U}<1 \%$ \\
\hline Low enriched U & $1 \%<{ }^{235} \mathrm{U}<20 \%$ \\
\hline High enriched $U$ & $>20 \%{ }^{235} \mathrm{U}$ \\
\hline
\end{tabular}

ITV uncertainty $\left(u_{c}\right)$ comprises two components; systemic uncertainty, $\mathrm{u}(\mathrm{s})$; and random uncertainty, $\mathrm{u}(\mathrm{r})$, determined by the percentage relative error (\% error) for accuracy and relative standard deviation ( $\%$ RSD) for precision measurements, respectively. It can be expressed as;

$$
u_{c}=\sqrt{\mathrm{u}(\mathrm{s})^{2}+\mathrm{u}(\mathrm{r})^{2}}
$$

To achieve adequate isotope-abundance measurements with high precision and accuracy of both radioactive and stable isotopes, IRMS employs a combination of high-energy ionization and double focusing mass analysis equipped with multiple Faraday-collector detectors to minimize correlated noise. ${ }^{16}$ For liquid samples, thermal-ionization mass spectrometry (TIMS) ${ }^{17}$ and inductively coupled plasma-mass spectrometry (ICP-MS) ${ }^{18}$ are employed. Direct analysis of solid materials requires laser ablation coupled to ICP-MS (LA-ICP-MS) ${ }^{19}$ or secondary ionization MS (SIMS) ${ }^{20}$ While these techniques still remain the gold-standard for isotopic assay, sample preparation and analysis are time-consuming and labor-intensive, making them less desirable for process control analysis and rapid detection. Additionally, the risk of transporting unknown materials from sites to an instrument in a controlled laboratory is also problematic. Thus, there is a need for development of field-deployable isotope assay technique for nuclear safeguards and forensics. While nuclear forensics is certainly a concern, nuclear safeguards and isotopic accounting are a more pressing need right now. The major consideration for implementation is the size, weight and power $(\mathrm{SWaP})$ requirements. 
Ion mobility spectrometry (IMS), when coupled to MS, is an emerging technique that could eliminate chemical interferences and consequently improve the signal-to-noise $(\mathrm{S} / \mathrm{N})$ ratio of the analyte of interest. The DMS post-ionization separation technique is rapid ( $\sim 3$ minutes), portable and inexpensive, making it a viable tool for on-site applications. Many researchers have reported the use of IMS for separation of organic species. More recently, it has been employed for the separation of elemental species and speciated forms of d- and f-block metals. ${ }^{21-24}$

In IMS, ions traverse through the drift tube under the influence of a low, static DC electric field. The ion's gas-phase mobility $\left(\mathrm{K}, \mathrm{cm}^{2} \mathrm{~s}^{-1} \mathrm{~V}^{-1}\right)$ through the tube is a function of their interaction with neutral species in their microscopic environment; measured by the ion-neutral collision cross section (CCS or $\Omega$ ). ${ }^{25,26}$ The ion mobility $(\mathrm{K})$ in the drift region is related to its velocity $\left(\mathrm{V}_{\mathrm{d}}, \mathrm{cm} \mathrm{s}^{-1}\right)$ under the influence of an electric field $\left(\mathrm{E}, \mathrm{V} \mathrm{cm}^{-1}\right)$ in the presence of a drift gas, given by:

$$
\mathrm{v}_{\mathrm{d}}=\mathrm{KE}
$$

A variant of IMS - differential mobility spectrometry (DMS), which is sometimes called field asymmetric waveform ion mobility spectrometry (FAIMS), ${ }^{27}$ was employed in this studies. Briefly on principle of operation, ions osciallate between two electrodes under the influence of a high AC electric field $(\geq 40 \mathrm{Td}$, where $1 \mathrm{Td} \approx 270 \mathrm{~V} / \mathrm{cm}$ for air at standard temperature and pressure). At such high fields, the relationship between $\mathrm{K}$ and $\Omega$ does not hold, and $\mathrm{Vd}$ is no longer proportional to $\mathrm{E}$. Thus, the mobility $\mathrm{K}$ becomes field dependent, ${ }^{28,29}$ represented as $\mathrm{K}(\mathrm{E})$ and simply expressed as:

$$
\mathrm{K}(\mathrm{E})=\mathrm{K}(0)\left[1+\alpha_{\mathrm{eff}}(\mathrm{E})\right]
$$

Where $\mathrm{K}(0)$ is the mobility coefficient of ion in low field conditions and $\alpha_{\mathrm{eff}}(\mathrm{E})$ is the effective alphaparameter function dependent on the electric field. Basically, $\alpha_{\text {eff }}(\mathrm{E})$ explains the interaction of an ion with a neutral (cluster-decluster, hard sphere or both) under the influence of the electric field. Detailed principles of the behavior of ion mobility as a function of DMS electric field has been explained elsewhere. $^{30-33}$

Briefly, an alternating low and high-field rf asymmetric waveform, termed dispersion voltage (DV) was applied to top electrode, as shown in Figure 1. Individual ions behave differently under the influence of this time-varying electric field and their net displacement as the drift through the DMS cell varies; some migrates towards the bottom electrode (type A ion); some towards the top electrode (type C ion); some initially migrate towards the bottom at low field and towards the top electrode at higher field (type B ion). In order to offset the migration of ions toward either top or bottom electrode, a constant DC voltage, termed compensation voltage $(\mathrm{CV})$, is applied on the top electrode, allowing transmission of ions with a narrow CCS through the device for MS detection. Each ion with different collision cross-sections has individual mobility characteristics, which results in different net displacements. Applying a CV scan (usually from negative to positive voltage) can be initially done to determine a CV value to filter out an ion. Hence, DMS is an ambient ion filter analogous to the quadrupole mass filter in vacuum system. Usually, DMS CV scans are performed in the timescale of milliseconds to a few seconds, and has been successfully coupled to MS for several applications. ${ }^{34-38}$ Previously, we have reported the implementation of DMS-MS for the separation and detection of inorganic species ${ }^{39,40}$ and, more recently, for the separation of metal complexes. ${ }^{41}$ 


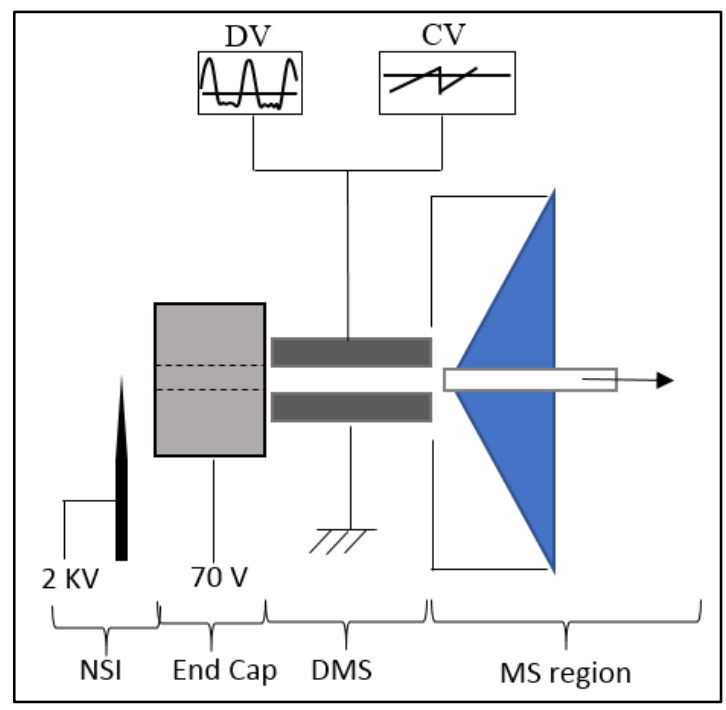

Figure 1. Schematics of nESI-DMS-MS setup

While DMS has demonstrated its capability for rapid ion pre-filtration, separation and elimination of chemical interference, the portability of DMS coupled to a fieldable MS system can be potentially used for field screening and characterization of radionuclides and their fission fragments. In this study, DMS was interfaced to nano electrospray ionization and the atmospheric-pressure inlet of an ion-trap MS. The resulting higher $\mathrm{S} / \mathrm{N}$ ratio due to DMS filtration, especially for low abundance isotopes, improved IR measurements accuracy.

\section{EXPERIMENTAL SECTION}

Sampling. Standard uranyl nitrate $\left[\mathrm{UO}_{2}\left(\mathrm{NO}_{3}\right)_{2} \cdot 6 \mathrm{H}_{2} \mathrm{O}\right]$ and strontium nitrate $\left[\mathrm{Sr}\left(\mathrm{NO}_{3}\right)_{2}\right]$ solutions were obtained from SPEX CertiPrep (Metuchen, NJ) at an initial concentration of $1000 \mu \mathrm{g} / \mathrm{ml}$ in water and nitric acid $(2 \% \mathrm{v} / \mathrm{v})$ solution. For speciation studies, solid uranyl acetate $\left.\left[\mathrm{UO}_{2}\left(\mathrm{C}_{2} \mathrm{H}_{3} \mathrm{O}_{2}\right)_{2} \cdot 2 \mathrm{H}_{2} \mathrm{O}\right)\right]$ was obtained from Baker and Adamson (Morristown, NJ). Solid lead nitrate was obtained from Acros organics (Pittsburgh, PA). For isotope studies, a certified reference material (CRM) of natural uranium (NIST SRM 3164), was obtained from High Purity Standards (Charleston, SC) as $1000 \mu \mathrm{g} / \mathrm{ml}$ in water and nitric acid (2\%) stock solution. Supplementary Table 1 shows the abundance of various isotopes and ${ }^{235} \mathrm{U} /{ }^{238} \mathrm{U}$ ratio obtained from the certificate of analysis. For safety reasons, it is noteworthy to mention that the uranyl salts were all in their depleted state, that is, the radioactive isotopes have been substantially reduced. Nitrates and acetate salts were further prepared in LC/MS grade methanol and 1:1 (v:v) methanol:water (Fisher Scientific Fair Lawn, NJ), to concentration ranges of $\mu \mathrm{M}$ and $\mathrm{mM}$, respectively, prior to MS analyses.

nESI-DMS-MS assembly. All sample solutions were introduced by direct infusion from a $500-\mu \mathrm{L}$ syringe (Hamilton Company Reno, NV) at $1 \mu \mathrm{L} / \mathrm{min}$ using the syringe pump built in to the mass spectrometer employed. The samples were ionized by a home-built nano-electrospray set-up ( $c f$. Figure 1) comprising a Picotip nanospray emitter with a 30- $\mu \mathrm{m}$ tip internal diameter (FS360-75-30-CE-5, New Objective Inc., Woburn, MA). A 2.0-kV high voltage was supplied from the commercial Thermo LTQ XL mass spectrometer (Thermo Fisher Scientific Inc., San Jose, CA). As shown in Figure 1, 70 V DC was supplied to the stainless steel end cap. The DMS electrodes were grounded, acting as a "braking" potential as described by Schneider et al, ${ }^{42}$ which effectively slows ion velocity relative to transport gas in the DMS drift region and consequentially reduces ion loss in the DMS-MS interface. However, the net ion-neutral 
flowrate is $0.65 \mathrm{~L} / \mathrm{min}$, solely dependent on vacuum pull from the MS. As shown in the section view in Figure 2 (left), the nano-electrospray emitter and the DMS electrodes maintained a 2 mm-distance from the end cap. The end cap with a hole of $1.5 \mathrm{~mm}$ ID and $7 \mathrm{~mm}$ depth was adhered using an O-ring to the front end of the DMS cell. The cell was tightly mounted to a flange originally designed for commercial Direct Analysis in Real Time (DART - Vapur IonSense Inc, Saugus, MA) to interface with the commercial Thermo LTQ XL MS for as described previously. ${ }^{43}$ Ions were transmitted through the DMS electrodes and finally into the mass-spectrometer through the inlet capillary set at $35 \mathrm{~V}$.

DMS instrumentation. The DMS cell and electronics employed here have been described previously. ${ }^{41,43}$ Briefly, Sionex flyback electronics (Sionex Corp., Bedford, MA) were used to drive the DMS and have the capacity of supplying dispersion voltages (DV) from 500 to $1500 \mathrm{~V}_{\mathrm{p}-\mathrm{p}}$ at $1.20 \mathrm{MHz}$ ( $c f$. Figure S-1) and compensation voltages $(\mathrm{CV})$ from -45 to $+15 \mathrm{~V}$. To obtain a full DMS dispersion plot, a method was programmed to scan a full DV and CV within $~ 5$ minutes; DV from 500 to $1500 \mathrm{~V}$ at $50-\mathrm{V}$ step sizes; at fixed DV, CV scan from -15 to $+9.5 \mathrm{~V}$ at incremental step size $0.5 \mathrm{~V}$ for $15 \mathrm{~s}$; equivalent to $\sim 1.667 \mathrm{~V} \mathrm{~s}^{-1}$. For uranium isotope measurement, the DMS method was set to a fixed DV and CV combination for a long MS acquisition time. Since only selected ions are filtered out, MS acquisition rate and mass range were adjusted to increase trapping capacity and improve ion signal.

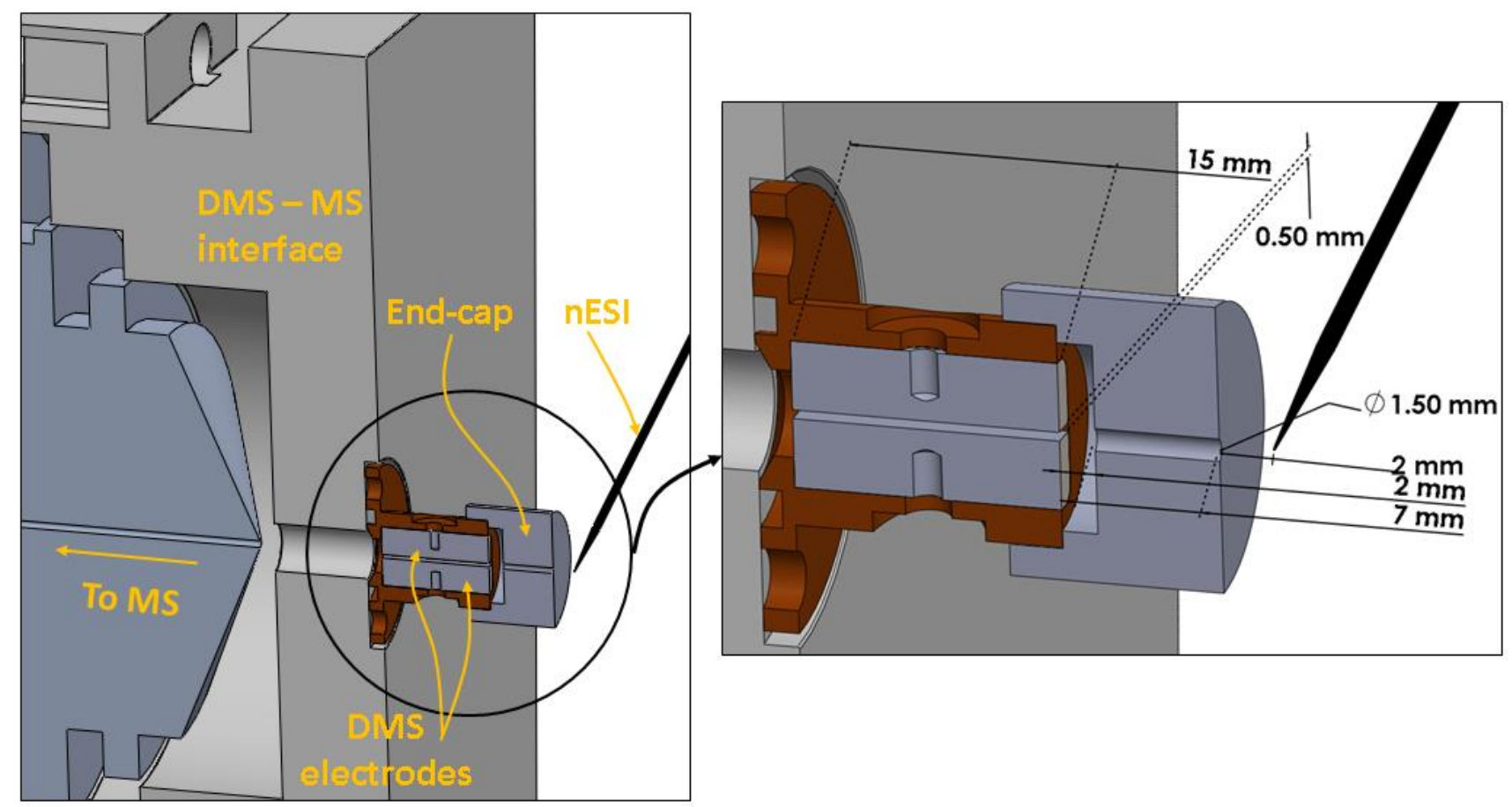

Figure 2. Detailed sectional view of the nESI-DMS-MS setup

MS parameters and data acquisition. A commercial linear ion-trap mass spectrometer (LTQ-XL, Thermo-Fisher Scientific Inc., San Jose, CA) was employed. The atmospheric-pressure interface (API) of the MS was optimized for maximum ion transmission for the DMS-MS hybrid; capillary inlet voltage and temperature were set to $35 \mathrm{~V}$ (as earlier mentioned) and $200{ }^{\circ} \mathrm{C}$, respectively; tube lens voltage at 115 Vwith automatic gain control (AGC) turned on. To detect the metal ion in the simplest form, the in-source collision-induced dissociation (CID) voltage was set to maximum (100 V). Mass spectra were acquired from the Thermo Xcalibur data acquisition software (version 4.0.27.10). For one microscan, , a maximum injection time of $10 \mathrm{~ms}$, and mass scan range of $m / z 50-500$ resulted in a maximum spectral acquisition 
rate of $\sim 8.4 \mathrm{~Hz}$. Hence, further MS acquisition rate study was done using a narrow mass range window of $\mathrm{m} / \mathrm{z} 265$ to 275 to increase the ion signal and trap capacity for uranyl ion $\left({ }^{235} \mathrm{UO}_{2}{ }^{+}\right.$and ${ }^{238} \mathrm{UO}_{2}{ }^{+}$at $m / z$ 267 and 270, respectively) for isotopic analysis. Different values of MS microscans and injection times and the impact on spectral acquisition rate were also explored and are shown in supplementary Figure S2 and Table S-1. From the result obtained, maximum microscan and maximum injection time values at 3 and $200 \mathrm{~ms}$, respectively was the most precise, and was employed for isotope-ratio measurement. Extracted ion signals were exported from Xcalibur MS to a programmed excel; capable of processing any DMS scan method in few seconds. DM Spectrum and dispersion plots were plotted using OriginPro 2015 (OriginLab Corp., Northampton, MA) software.

\section{RESULTS AND DISCUSSION}

\section{DMS Reproducibility Studies}

For a 20-mM uranyl acetate solution, repeated DMS CV scans $(-15$ to $+9.5 \mathrm{~V})$ of the $\mathrm{UO}_{2}{ }^{+}$ion were obtained at a fixed DV of $1200 \mathrm{~V}$ at different DMS CV scan rates as shown in Figure 3. The integrated ion signal for 20 differential mobility peaks were obtained and averaged for each scan duration (Table 2).

The precision, measured as the relative standard deviation (RSD) of $20 \mathrm{CV}$ scans, improved as the CV scan duration increased. Better precision at longer DMS scan times was expected since the number of mass-spectral scans also increased. However, the reproducibility of the DMS scan rate was investigated in Error! Reference source not found. showing the integrated ion signal plotted against the CV scan duration. The correlation coefficient of the linear fit shows that using the DMS may have potential for quantitative analysis. It is worth noting that the reproducibility of ion signal also depends on the stability of the ion current from the source. Additionally, the CV value where the dispersed ion peak (left intense peak) was filtered is another index of DMS reproducibility. The CV and $\sigma$ value in each CV scan duration is reported in supplementary Figure S-4. An overlaid DM spectrum indicates that the dispersed ion peak (DIP) of uranyl ion were filtered out at $\mathrm{CV} \sim 10 \mathrm{~V}$, with no visible peak shift. However, further study was conducted to confirm that there is no ion peak shift on the DM Spectrum at variable MS acquisition rate. At fixed DV $1200 \mathrm{~V}$ and CV scan of -15 to $+9.5 \mathrm{~V}$ for $15 \mathrm{sec}, \mathrm{UO}_{2}{ }^{+}$dispersed ion peak (DIP) were all filtered out at a visible CV value of $\sim-10 \mathrm{~V}$ as shown in supplementary Figure S-3. 


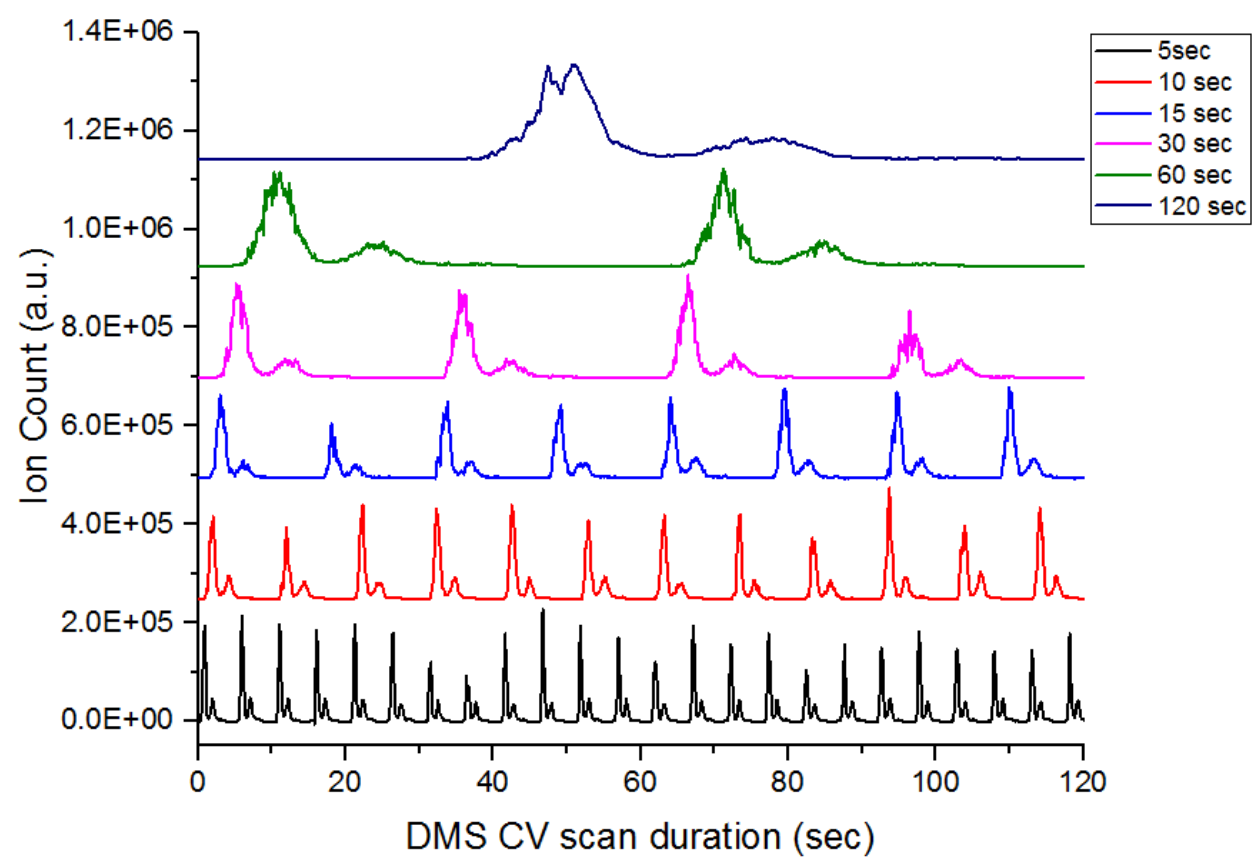

Figure 3. At fixed DV $1200 \mathrm{~V}$, DMS scan of $\mathrm{UO}_{2}+$ ion for twenty repeated CV scans from -15 to $+9.5 \mathrm{~V}$ at different duration obtained at $20 \mathrm{mM}$ uranyl acetate solution.

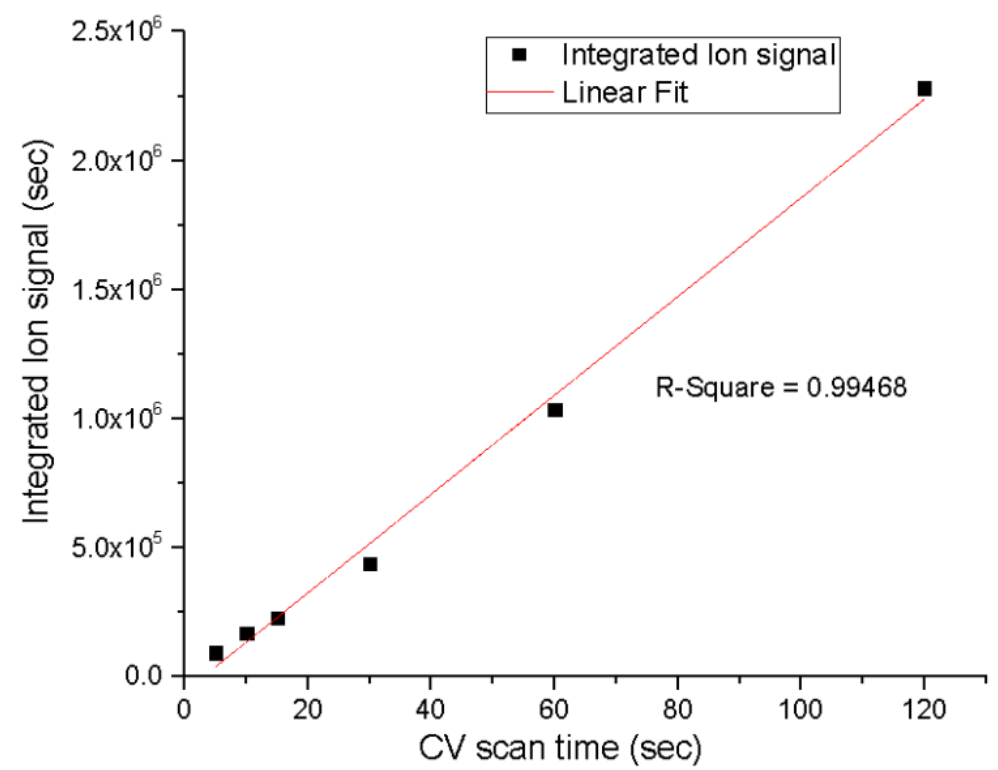

Figure 4. Integrated ion signal of $\mathrm{UO}_{2}{ }^{+}$ion show linearity as the $\mathrm{CV}$ scan increases. 
Table 2. Integrated Ion Signal of Uranyl ion at different DMS CV scan duration.

\begin{tabular}{l|llllll}
\hline Time (s) & 5 & 10 & 15 & 30 & 60 & 120 \\
\hline Average Integrated & & & & & & \\
Ion Signal (s) & $9.50 \mathrm{E}+04$ & $1.71 \mathrm{E}+05$ & $2.30 \mathrm{E}+05$ & $4.41 \mathrm{E}+05$ & $1.04 \mathrm{E}+06$ & $2.28 \mathrm{E}+06$ \\
SD (s) & $1.46 \mathrm{E}+04$ & $2.45 \mathrm{E}+04$ & $3.56 \mathrm{E}+04$ & $6.16 \mathrm{E}+04$ & $1.16 \mathrm{E}+05$ & $1.64 \mathrm{E}+05$ \\
RSD (\%) & 15.35 & 14.35 & 15.43 & 13.97 & 11.21 & 7.21 \\
\hline
\end{tabular}




\section{Pre-filtration and separation of Uranyl salts from sample mixture}

A mixture of uranyl nitrate and strontium nitrate salts were prepared at $4-\mu \mathrm{M}$ concentration in methanol solution. Strontium was selected because of its availability and relative stability as fission product. When a full DV and CV scan was obtained for the sprayed mixture, the full dispersion plots of $\mathrm{UO}_{2}{ }^{+}$and $\mathrm{SrOH}^{+}$ were obtained. From the dispersion plot, a DM spectrum of both ions were extracted (Figure 5a) at a DV $1000 \mathrm{~V}$. From this result, the $\mathrm{SrOH}^{+}$ion experiences greater field dispersion (more negative $\mathrm{CV}$ ) than the $\mathrm{UO}_{2}{ }^{+}$. As predicted from previous literature, smaller molecules tends to be filtered at more negative $\mathrm{CV}$ values $^{44}$; that is, they exhibit more of type $\mathrm{A}$ ion behavior with ion mobility coefficients $\alpha(\mathrm{E} / \mathrm{N})>>0$. In our DMS design, the DV is applied to the top electrode, while the $\mathrm{SrOH}^{+}$ion is displaced more toward the bottom electrode than the $\mathrm{UO}_{2}{ }^{+}$ion. In order to offset the displacement and allow ions of interest to pass through the electrode gaps for detection, $\mathrm{CVs}$ of $-11.5 \mathrm{~V}$ and $-8.6 \mathrm{~V}$ were superimposed on the top electrodes to transmit $\mathrm{SrOH}^{+}$and $\mathrm{UO}_{2}{ }^{+}$ion, respectively. In this case, the $\mathrm{UO}_{2}{ }^{+}$dispersed ion peak is $c a$. ten-fold greater than $\mathrm{SrOH}^{+}$ion even though their mole ratio in the solution phase sample is in ratio 1:1. This evidence suggests that the behavior of ESI ion in gas phase is not a true representation of its actual sample composition in condense phase, due to undetermined matrix effects as has been seen by others

.${ }^{45,46}$ The mass spectrum of the mixture when DMS DV and CV is off (transparent mode) is shown in Figure $5 \mathrm{~b}$ (top). The peaks of interest are $\mathrm{UO}_{2}{ }^{+}$and $\mathrm{SrOH}^{+}$at; $m / z 270$ (base peak) and 104.8, respectively.

\section{DMS for Isotope measurement}

In this study, natural uranium of ${ }^{235} \mathrm{U}$ isotope is $<1 \%$ was employed. In order to obtain quantifiable signal of this minor isotopes, high concentration sampling is highly recommended for isotope measurement. It is also imperative to mention that there is reduced ion transmission when DMS is coupled to MS, as described in previous literatures. ${ }^{47,48}$ For our planar DMS design, ion signal was reduced by a factor of $\sim 10$. However, increasing sample concentration can compensate for the ion loss. In order to establish the performance of DMS-MS system for IR measurements, preliminary isotope study was performed on uranyl nitrate standard at $500 \mu \mathrm{M}$ concentration. With the DMS "off", an unknown ionic species interferes with the ${ }^{235} \mathrm{UO}_{2}{ }^{+}$ion at $\mathrm{m} / \mathrm{z} 267$ which resulted in the high ${ }^{235} \mathrm{UO}_{2}{ }^{+} / 235 \mathrm{UO}_{2}{ }^{+}$ratio of 0.349335 as shown in the mass spectrum in Figure 6. The result clearl indicates that ${ }^{235} \mathrm{UO}_{2}{ }^{+} / 238 \mathrm{UO}_{2}{ }^{+}$ratio may not be accurately measured on a conventional trap-styled MS analyzer with low mass resolution. Even on high resolution MS, background noise could overlap on minor isotopes thus affecting the accuracy of IR measurement. Studies have explained that space-charge effect, background noise, and automatic background deletion (that is, " 0 " background) at the present threshold created a bias that favors the most abundant isotope relative to the minor isotopes, thus further impairing the accuracy of the IR measurement. ${ }^{49,50}$ While employing DMS, a 5-minute DV and CV scan was conducted to obtain a full dispersion plot. From the dispersion plot, DV $1300 \mathrm{~V}$ and CV $-10.5 \mathrm{~V}$ was selected to transmit only the $\mathrm{UO}_{2}{ }^{+}$ion. At the fixed DV and $\mathrm{CV}$ combination, uranyl ion was transmitted and acquired in 30 minutes. The ${ }^{235} \mathrm{UO}_{2}{ }^{+} / 238 \mathrm{UO}_{2}{ }^{+}$ratio was measured as 0.007077 as shown in Figure 6. 

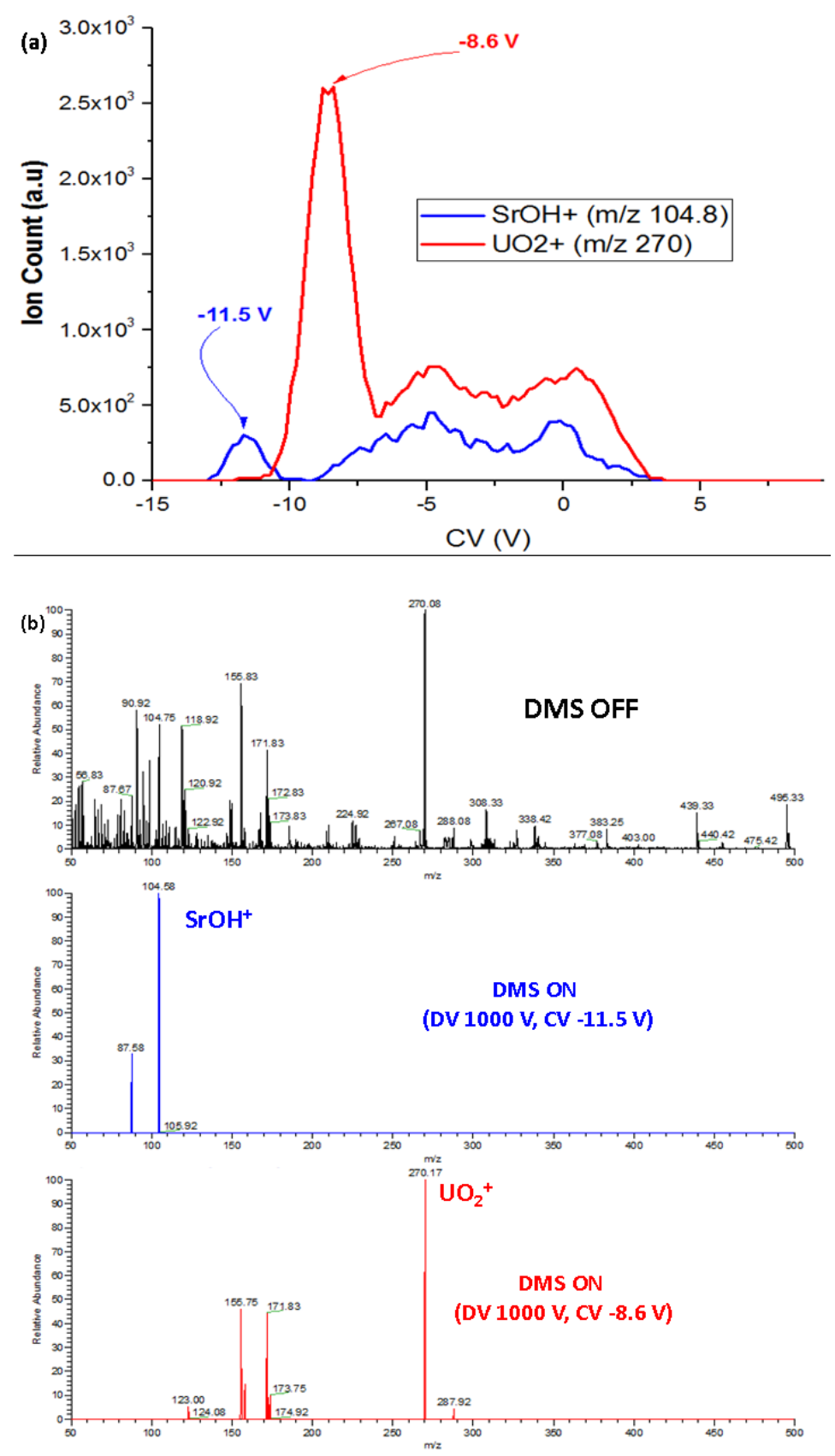

Figure 5. (a) At fixed DV 1000 from the dispersion plots produces the overlayed DM spectrum (right). (b) Mass spectrum of sample mixture at DMS off i.e. at no DV and CV scan or "transparent" mode (top), and DMS DV $1000 \mathrm{~V}$, and $\mathrm{CV}-11.5 \mathrm{~V}$ and $-8.5 \mathrm{~V}$ for filter $\mathrm{SrOH}^{+}$(middle) and $\mathrm{UO}_{2}^{+}$(bottom) ion, respectively. 


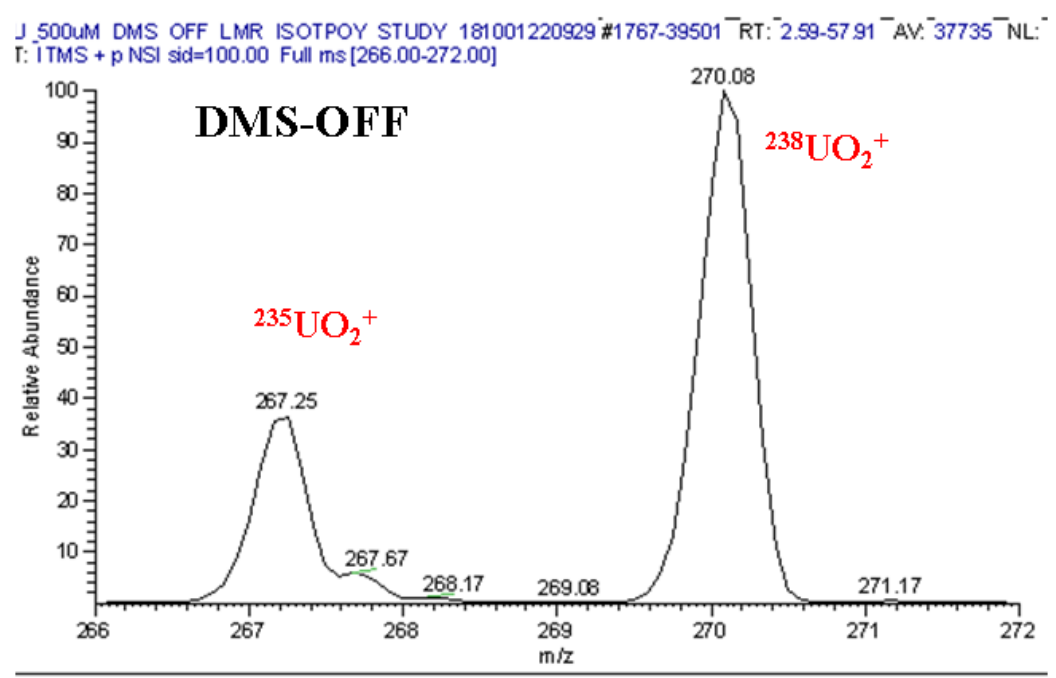

J_500uM_DMS_ON_LMR_neg_10_55_ISOTOPY_STUDY_181001220929 \#103-2614 RT: 1.35-35.29 AV. $\mathrm{T}:$ ITMS + p NSI sid $=100.00$ Full $\mathrm{ms}[2 \overline{6} 6.00-272.00]$

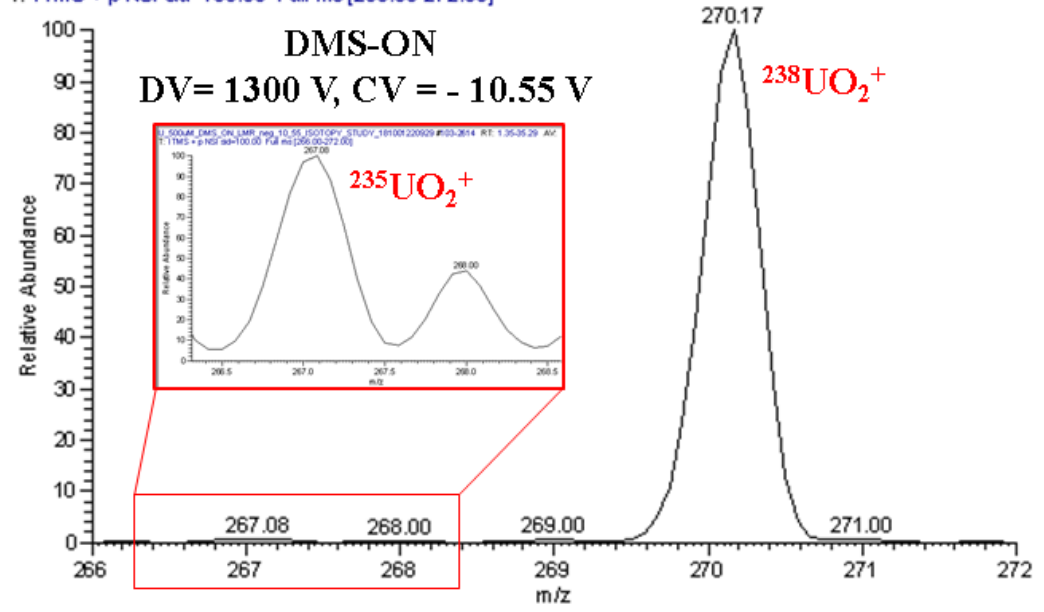

$$
\begin{aligned}
& { }^{235} \mathrm{UO}_{\mathbf{2}}{ }^{+} /{ }^{+238} \mathrm{UO}_{2}{ }^{+} \text {ratio } \\
& \begin{array}{|l|l|l|}
\hline & \text { Average } & \text { SD } \\
\hline \text { DMS OFF } & 0.349335 & 0.061379 \\
\hline \text { DMS ON } & 0.007077 & 0.006768 \\
\hline
\end{array}
\end{aligned}
$$

Figure 6. Uranyl nitrate mass spectrum: Peaks of ${ }^{235} \mathrm{UO}_{2}{ }^{+}$and ${ }^{238} \mathrm{UO}_{2}{ }^{+}$ions at $\mathrm{m} / \mathrm{z} 267$ and 270 , respectively at DMS OFF and DMS ON (DV $1300 \mathrm{~V}$ and CV -10.5 V). Inset is a scale expansion showing of ${ }^{235} \mathrm{UO}_{2}{ }^{+}$at DMS ON. 
After a 5-month period, at the same experimental conditions including sample preparation, DMS and MS instrumental conditions, the experiment was repeated. At the DV $1300 \mathrm{~V}$ and CV $-11.6 \mathrm{~V}$ combination we obtained from the dispersion plot (not shown) for uranyl ion isotope measurement. The IR measurement obtained was $0.006884 \pm 0.001109$. The $1.38 \%$ relative standard deviation (RSD) confirmed DMS reproducibility, which promises a potential methodology for portable isotope measurements of uranium. We note here that the CV shift is not unusual in ion mobility phenomena. The underlying principle of DMS separation involves the interaction of ions with neutral gas in ambient environment. However, variables in such environment which include temperature, pressure and humidity will influence the ion-neutral interaction as they drift through the DMS cell, and thus consequently affect the net displacement in CV values of ions.

To further validate the performance of the DMS-MS hybrid, the isotope study was conducted on a certified natural uranium (NIST SRM 3164). The ${ }^{235} \mathrm{U} /{ }^{238} \mathrm{U}$ ratio was certified as 0.007261 based on preparation and analytical method developed at NIST for SRM spectrometric standard solution. As shown in Error! Reference source not found., for the 5-minute dispersion plot (Figure 7a), a DV and CV of $1000 \mathrm{~V}$ and $-7.8 \mathrm{~V}$ were selected and held for 30 minutes at MS scan rate of 1.232 $\mathrm{Hz}$ and in a tight mass range window $\mathrm{m} / \mathrm{z} 265-275$; equivalent to 2217 data points. As shown in Figure $7 \mathrm{~b}$ (top), the total ion signal dropped by a factor of 0.1 when DMS is turned on and the corresponding mass spectrum for the 30 -minute DMS run time is shown at the bottom.

As observed in the mass spectrum, the ${ }^{235} \mathrm{UO}_{2}{ }^{+}$and ${ }^{238} \mathrm{UO}_{2}{ }^{+}$peaks at $\mathrm{m} / \mathrm{z} 267$ and 270 were distinctly observed and baseline resolved with interfering background signal $\sim 0$. By visual examination, the $\mathrm{y}-$ axis zoom in (Figure $7 \mathrm{~b}$ ), the percentage isotope abundance of the minor isotope; ${ }^{235} \mathrm{UO}_{2}{ }^{+}$ion can be observed as $\sim 0.7 \%$. Further analysis of the extraction ion chromatogram of $\mathrm{m} / \mathrm{z} 267$ and 270 corresponding to ${ }^{235} \mathrm{UO}_{2}{ }^{+}$and ${ }^{238} \mathrm{UO}_{2}{ }^{+}$ion, respectively were obtained from the 30 minutes scan. The ${ }^{235} \mathrm{UO}_{2}{ }^{+} /{ }^{238} \mathrm{UO}_{2}{ }^{+}$ratio was measured as 0.007126 . Conversely, while DMS potentials were turned off (transparent mode); that is all ions were allowed to pass through, the ratio was recorded as 0.00913 as detailed in Figure 8 (top). In order to validate the reliability of our result in accordance with the International Target values (ITV) guideline, the $\mathrm{u}(\mathrm{r}) \% \mathrm{RSD}$ and $\mathrm{u}(\mathrm{s}) \%$ relative RD were measured as shown in Figure 8 (bottom). From the result, the combined (total) standard uncertainty $\left(u_{c}\right)$ at DMS ON and OFF were calculated as $7.214 \%$ and $26.58 \%$, respectively (calculation shown in supplementary materials). The low value $\left(u_{c}\right)$ obtained while DMS is ON clearly indicates improved accuracy and precision. In our case, natural U was employed for safety reasons, with lower U-235/U-238 ratio. This implies that we expect to have a lower signal/noise ratio for U-235, compare to a sampled to analyzing a LEU or HEU. From the ITV classification, natural $\mathrm{U}\left(0.3 \%<{ }^{235} \mathrm{U}<1 \%\right)$ should have ITV $\left(u_{c}\right)$ of $0.28 .{ }^{15,50}$ Although, our result is on the high side which could be attributed to the low abundance of U-235. Some previous works have conducted uranium IR measurement on varieties of high resolution MS and compared analysis time (1- 9 hours) and results. ${ }^{50}$ In the experiment, analysis was done on Low Enriched Uranium(LEU) to High Enriched Uranium (HEU). The novelty of our DMS-MS for IR measurement was that we can conduct IR measurement in $\sim 30$ minute run time on natural $U$, with lower U-235 abundance, compared to the LEU and HEU, making it a potential fieldable technique for rapid IR measurement. 


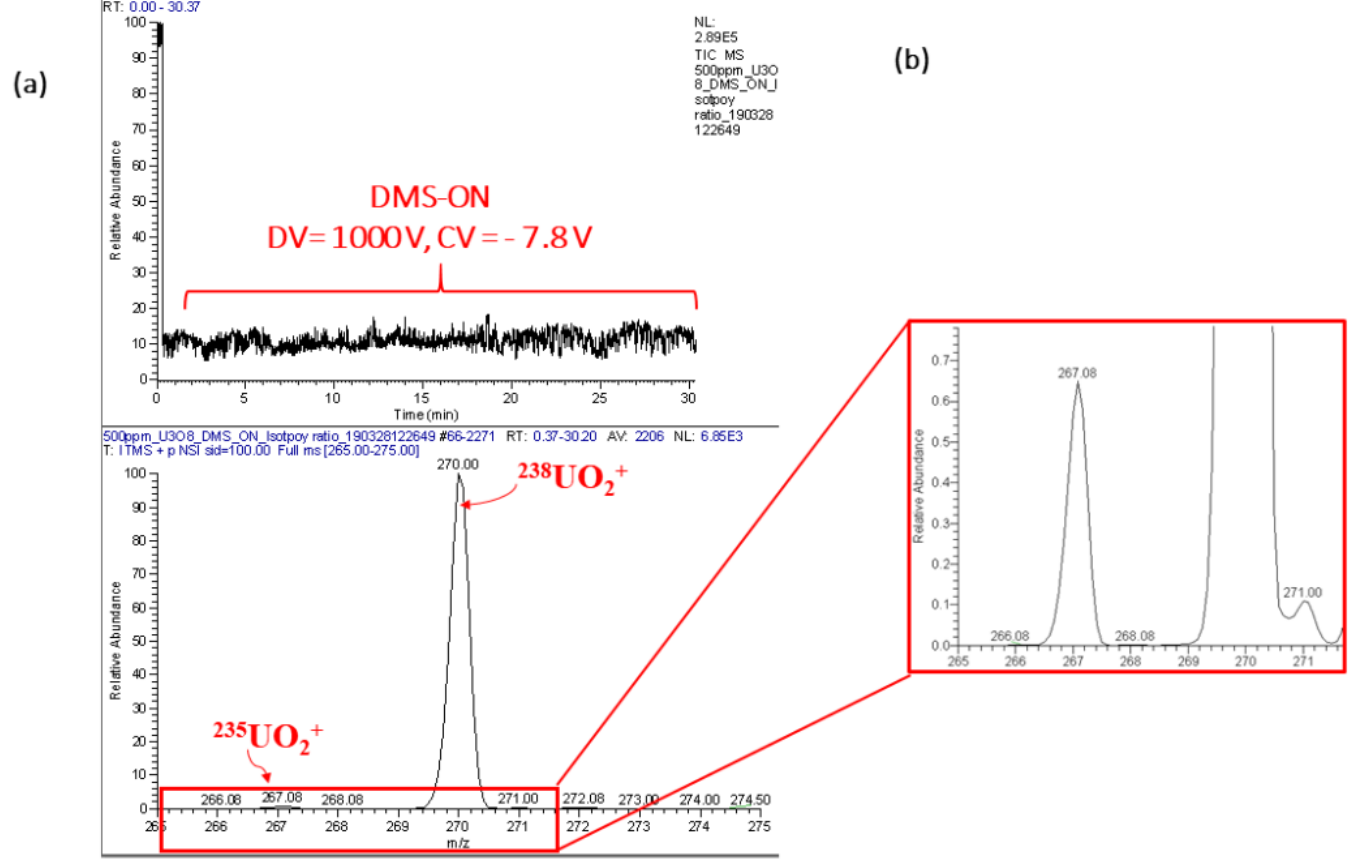

Figure 7. (a) At DMS on; fixed DV and CV values of $1000 \mathrm{~V}$ and $-7.8 \mathrm{~V}, 30$ minutes filtration (top) of $\mathrm{UO} 2+$ ion for isotope measurement of ${ }^{235} \mathrm{UO}_{2}{ }^{+} /{ }^{238} \mathrm{UO}_{2}+$ ratio. Corresponding mass spectrum (bottom) and (b) y -axis zoomed in mass spectrum of ${ }^{235} \mathrm{UO}_{2}{ }^{+}$isotope. 

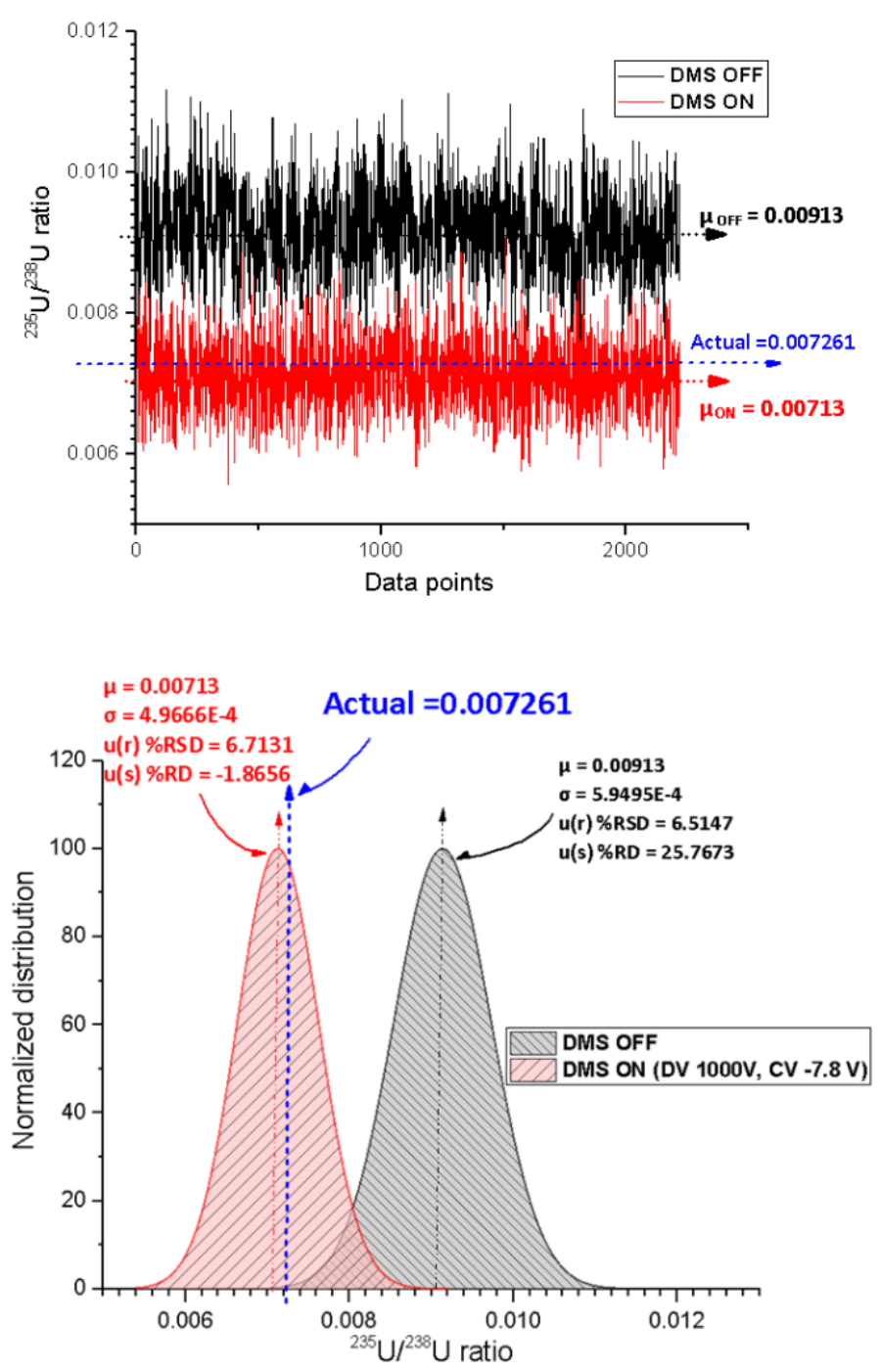

Figure 8. Isotope ratio measurement of ${ }^{235} \mathrm{U} /{ }^{238} \mathrm{U}$ ratio at DMS ON and OFF (top), and normal distribution curve (bottom) of the IR measurements. 
In order to validate the performance of DMS in a sample containing a heterogeneous mixtures of uranium and lead. SRM of uranium was spiked with lead nitrate $\left(\mathrm{Pb}\left(\mathrm{NO}_{3}\right)_{2}\right)$ at concentration ratio $\mathrm{SRM}: \mathrm{Pb}\left(\mathrm{NO}_{3}\right)_{2}=10: 1$, producing $\mathrm{Pb}\left(\mathrm{NO}_{3}\right)^{+}$ion (mass spectrum in supplementary figure $\mathrm{S} 3$ ) which creates an isobaric interference with ${ }^{238} \mathrm{UO}_{2}{ }^{+}$at $\mathrm{m} / \mathrm{z} 270$. At DV $800 \mathrm{~V}$, the DM spectrum obtained shows the separation of $\mathrm{UO}_{2}{ }^{+}$from $\mathrm{Pb}\left(\mathrm{NO}_{3}\right)^{+}$ion, as shown in figure 10 (top). While $\mathrm{Pb}-$ 206 and $\mathrm{Pb}-208$ isotopes were expected to be filtered out at the same DMS field, the ${ }^{206} \mathrm{~Pb}(\mathrm{NO}) 3^{+}$ extracted ion chromatogram (EIC), equivalent to $\mathrm{m} / \mathrm{z} 268$ will have similar peak as the ${ }^{208} \mathrm{~Pb}(\mathrm{NO}) 3^{+}$ pair. The corresponding mass spectrum (figure 10- bottom) conducted with DMS "ON" and "OFF" is shown. From the result, the base peak $(\mathrm{m} / \mathrm{z} 270)$ is associated to ${ }^{238} \mathrm{UO}_{2}{ }^{+}$and ${ }^{208} \mathrm{~Pb}(\mathrm{NO}){ }_{3}{ }^{+}$ions while the zoomed in inset shows the ${ }^{235} \mathrm{UO}_{2}{ }^{+}$while DMS is ON and OFF. At the fixed DV 800V ands CV -7.8 V, IR measurement was obtained, ranging from 5 minutes to about 75 minutes, result obtained were summarized in table 2 . For 30 minutes acquisition time, a comparison of IR measurement for neat SRM sample $\left({ }^{235} \mathrm{UO}_{2}{ }^{+} /{ }^{238} \mathrm{UO}_{2}{ }^{+}=0.00713\right)$ with spiked SRM $\left({ }^{235} \mathrm{UO}_{2}{ }^{+} /\right.$ ${ }^{238} \mathrm{UO}_{2}{ }^{+}=0.00745$ ) for a 30 minutes acquisition time, shows $\sim 4 \%$ increase. This deviation is not significant relative to the result obtained with the DMS "OFF" $\left({ }^{235} \mathrm{UO}_{2}{ }^{+} /{ }^{238} \mathrm{UO}_{2}{ }^{+}=0.02082\right)$. The substantial increase in ratio can be attributed to the presence of the isobaric interference of $\mathrm{Pb}$ $\left(\mathrm{NO}_{3}\right)^{+}$ion at $\mathrm{m} / \mathrm{z} 270$. As a rule of thumb, we expect the RSD value to reduce as time increases, in these studies, the \% error is more important than RSD. From Table 3 we can infer that 15 minutes DMS scan gave the best IR measurement result with \% error of 2.62 . 

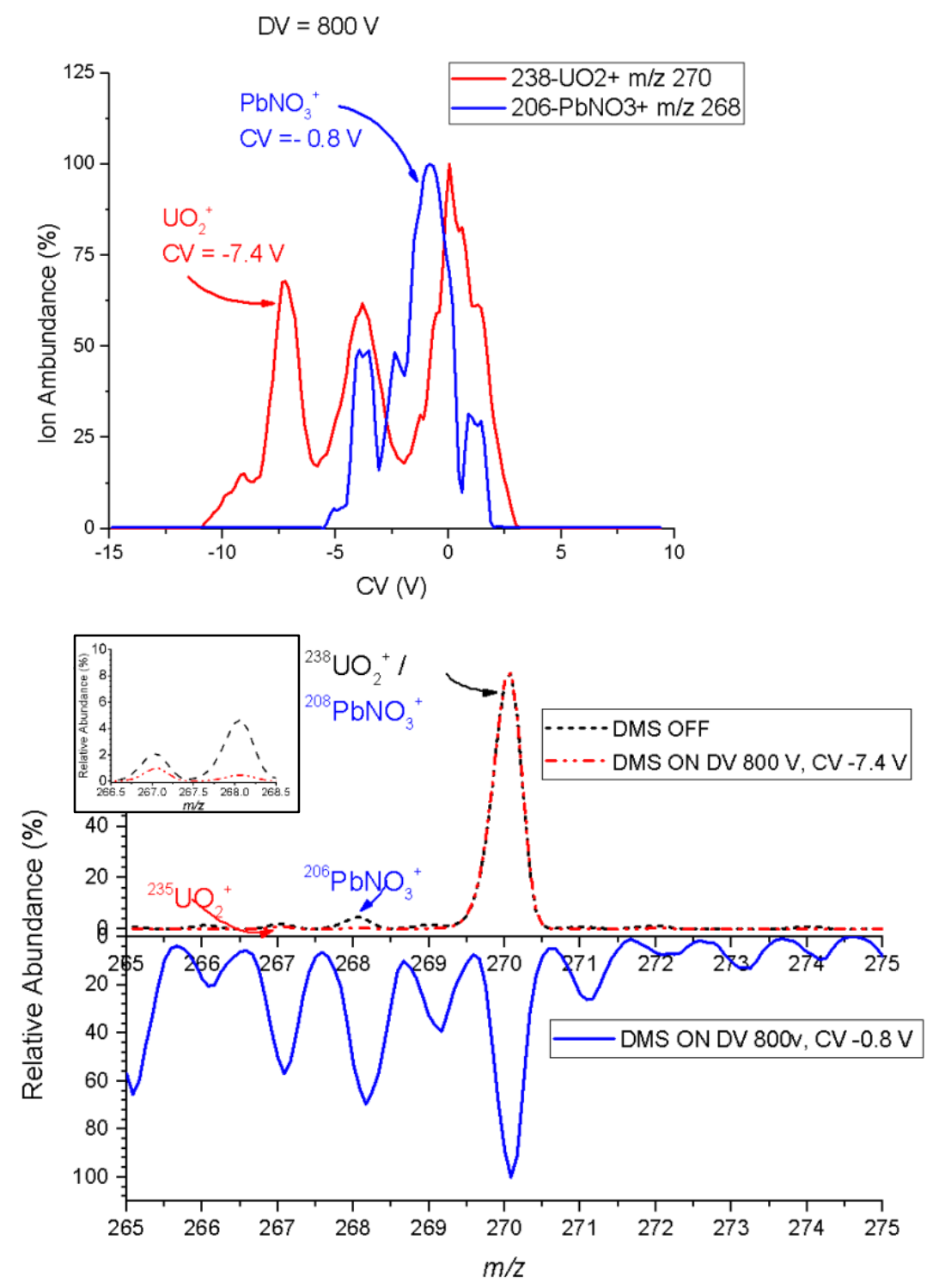

Figure 9. DM-spectrum showing separation mixtures of SRM and lead nitrate (top), and corresponding mass spectrum. 
Table 3. IR measurement of ${ }^{235} \mathrm{UO}_{2}{ }^{+} /{ }^{238} \mathrm{UO}_{2}{ }^{+}$measured at different time ranges.

\begin{tabular}{|l|l|l|l|l|}
\hline DMS ON & \multicolumn{2}{|l|}{ DV 800 V, CV -7.4 V } & & \\
\hline Time (min) & Average & $\sigma$ & $\begin{array}{l}\text { RSD } \\
\mathrm{u}(\mathrm{r})\end{array}$ & \% error (u (s) \\
\hline 5 & 0.00754 & 0.00367 & 48.66 & 3.89 \\
\hline 15 & 0.00745 & 0.00335 & 44.91 & 2.62 \\
\hline 30 & 0.00751 & 0.00305 & 40.80 & 3.42 \\
\hline 45 & 0.00773 & 0.00297 & 38.40 & 6.40 \\
\hline 60 & 0.00783 & 0.00281 & 35.92 & 7.89 \\
\hline 75 & 0.00817 & 0.00421 & 52.78 & 12.46 \\
\hline & & & & \\
\hline DMS OFF & & & & \\
\hline 30 & 0.02082 & 0.00719 & 34.53 & 186.69 \\
\hline & & & & \\
\hline ACTUAL & 0.007261 & & & \\
\hline
\end{tabular}

\section{CONCLUSION}

In our previous study, we have established the feasibility of DMS for prefiltration and separation of inorganic complex mixtures.$^{51}$ Herein, the study was aimed at extending the DMS-Ion trap MS hybrid as a potential portable system for the separation and characterization of uranium and strontium from mixtures; analogous to radionuclear fission products. Solution of sample mixtures were nanospayed to produce gas phase oxides including; uranyl ion $\left(\mathrm{UO}_{2}{ }^{+}\right)$, strontium hydroxide ion $\left(\mathrm{SrOH}^{+}\right)$, and other interfering chemical species. A rapid DV and $\mathrm{CV}$ gradient scan was applied to the DMS electrodes to selectively filter out each ionic species as they drift through the DMS cell within $\sim 5$ minutes, prior to MS detection. Full dispersion plots were obtained from MS data and a nominal 15 seconds CV scan DM-spectrum was derived from a fixed DV of the dispersion plot. Our result shows that DMS was capable of separating uranyl and strontium species from each 
other, and from interfering peaks. From the DM spectrum, fixed DV and CV combination was obtained for the uranyl ion to further conduct an isotope ratio measurement. DMS filtered MS analysis with single ion monitoring was conducted for $\sim 30$ minutes to obtain the relative isotopic abundances of U-235 and U-238. IR measurements were compared to results obtained with the DMS “off". From our results, the capability of DMS to remove interfering peaks on the less abundant isotope (U-235) indicates a potential use for satisfactory IR measurements from common and inexpensive MS instrumentation relative to gold standard magnetic sectors. For further validation, the same experiment was performed on a certified reference material of natural uranium, spiked with an isobaric contaminant. Results indicate that the portability of DMS can be coupled to an ion trap style analyzer that is often the basis for portable MS systems to potentially supply characterization and isotope measurement of radionuclear materials. Additionally, DMS can be potentially coupled to the conventional IRMS, serving as an orthogonal pre-filtration technique, and subsequently improve confidence of nuclear isotope assay result, specified by International Target Values (ITV).

\section{ASSOCIATED CONTENT}

Supporting Information is provided as Figures S-1 - S-4 and Table S-1 - S-2 available free of charge on publications website.

\section{AUTHOR INFORMATION}

Corresponding Author

*Address: CHE205, 4202 East Fowler Ave, Tampa, FL 33620. Tel. 813-974-9633. E-mail: evansnguyen@usf.edu

\section{ACKNOWLEDGEMENTS}

We thank Shelley's group for giving us opportunity to conduct preliminary experiment for uranium isotope measurement in their lab at Rensselaer Polytechnic Institute.

\section{REFERENCES}

(1) Lovering, J. R.; Yip, A.; Nordhaus, T. Historical Construction Costs of Global Nuclear Power Reactors. Energy Policy 2016, 91, 371-382. https://doi.org/10.1016/j.enpol.2016.01.011.

(2) Lau, L.-S.; Choong, C.-K.; Ng, C.-F.; Liew, F.-M.; Ching, S.-L. Is Nuclear Energy Clean? Revisit of Environmental Kuznets Curve Hypothesis in OECD Countries. Economic Modelling 2019, 77, 1220. https://doi.org/10.1016/j.econmod.2018.09.015.

(3) Fukushima accident | Summary, Effects, \& Facts https://www.britannica.com/event/Fukushimaaccident (accessed May 17, 2019). 
(4) Sciences, N. A. of. Correction for Yasunari et al., Cesium-137 Deposition and Contamination of Japanese Soils Due to the Fukushima Nuclear Accident. PNAS 2013, 110 (18), 7525-7528.

https://doi.org/10.1073/pnas.1301231110.

(5) Visschers, V. H. M.; Siegrist, M. How a Nuclear Power Plant Accident Influences Acceptance of Nuclear Power: Results of a Longitudinal Study Before and After the Fukushima Disaster. Risk Analysis 2013, 33 (2), 333-347. https://doi.org/10.1111/j.1539-6924.2012.01861.x.

(6) Wang, S.; Wang, J.; Lin, S.; Li, J. Public Perceptions and Acceptance of Nuclear Energy in China: The Role of Public Knowledge, Perceived Benefit, Perceived Risk and Public Engagement. Energy Policy 2019, 126, 352-360. https://doi.org/10.1016/j.enpol.2018.11.040.

(7) Safeguards Techniques and Equipment, 2011 edition.; International Atomic Engergy Agency, Ed.; International nuclear verification series; International Atomic Energy Agency: Vienna, 2011.

(8) Read "Improving the Scientific Basis for Managing DOE's Excess Nuclear Materials and Spent Nuclear Fuel" at NAP.Edu. https://doi.org/10.17226/10684.

(9) Kovacs, T.; Jr, A. P. M.; Pfeiffer, L. N. Geiger-Mueller Radiation Detector with Means for Detecting and Indicating the Existence of Radiation Overload. US4260892A, April 7, 1981.

(10) Inc, V. T. Nuclear Forensic Analysis 1st edition | 9780849315138 https://www.vitalsource.com/products/nuclear-forensic-analysis-kenton-j-moodyv9780203507803 (accessed May 17, 2019).

(11) Nuclear Forensic Analysis https://www.crcpress.com/Nuclear-Forensic-Analysis-SecondEdition/Moody-Grant-Hutcheon/p/book/9781439880616 (accessed May 17, 2019).

(12) Mayer, K.; Wallenius, M.; Ray, I. Nuclear Forensics-a Methodology Providing Clues on the Origin of Illicitly Trafficked Nuclear Materials. Analyst 2005, 130 (4), 433-441.

https://doi.org/10.1039/B412922A.

(13) Stanley, F. E.; Stalcup, A. M.; Spitz, H. B. A Brief Introduction to Analytical Methods in Nuclear Forensics. J Radioanal Nucl Chem 2013, 295 (2), 1385-1393. https://doi.org/10.1007/s10967012-1927-3.

(14) Kristo, M. J.; Gaffney, A. M.; Marks, N.; Knight, K.; Cassata, W. S.; Hutcheon, I. D. Nuclear Forensic Science: Analysis of Nuclear Material Out of Regulatory Control. Annual Review of Earth and Planetary Sciences 2016, 44 (1), 555-579. https://doi.org/10.1146/annurev-earth-060115012309.

(15) Zhao, K.; Penkin, M.; Norman, C.; Balsley, S. International Target Values 2010 for Measurement Uncertainties in Safeguarding Nuclear Materials. ESARDA Bulletin 2012, 48, 3-24.

(16) Vanhaecke, F.; Moens, L.; Dams, R.; Taylor, P. Precise Measurement of Isotope Ratios with a Double-Focusing Magnetic Sector ICP Mass Spectrometer. Anal. Chem. 1996, 68 (3), 567-569. https://doi.org/10.1021/ac9507247.

(17) Byerly, B. L.; Stanley, F.; Spencer, K.; Colletti, L.; Garduno, K.; Kuhn, K.; Lujan, E.; Martinez, A.; Porterfield, D.; Rim, J.; Schappert, M.; Thomas, M.; Townsend, L.; Xu, N.; Tandon, L. Forensic Investigation of Plutonium Metal: A Case Study of CRM 126. J Radioanal Nucl Chem 2016, 310 (2), 623-632. https://doi.org/10.1007/s10967-016-4919-x.

(18) Magara, M.; Hanzawa, Y.; Esaka, F.; Miyamoto, Y.; Yasuda, K.; Watanabe, K.; Usuda, S.; Nishimura, H.; Adachi, T. Development of Analytical Techniques for Ultra Trace Amounts of Nuclear Materials in Environmental Samples Using ICP-MS for Safeguards. Applied Radiation and Isotopes 2000, 53 (1), 87-90. https://doi.org/10.1016/S0969-8043(00)00117-2.

(19) T. Manard, B.; Quarles, C. D.; Miller Wylie, E.; Xu, N. Laser Ablation - Inductively Couple Plasma Mass Spectrometry/Laser Induced Break down Spectroscopy: A Tandem Technique for Uranium Particle Characterization. Journal of Analytical Atomic Spectrometry 2017, 32 (9), 1680-1687. https://doi.org/10.1039/C7JA00102A. 
(20) Erdmann, N.; Betti, M.; Stetzer, O.; Tamborini, G.; Kratz, J. V.; Trautmann, N.; van Geel, J. Production of Monodisperse Uranium Oxide Particles and Their Characterization by Scanning Electron Microscopy and Secondary Ion Mass Spectrometry. Spectrochimica Acta Part B: Atomic Spectroscopy 2000, 55 (10), 1565-1575. https://doi.org/10.1016/S0584-8547(00)00262-7.

(21) Ilbeigi, V.; Valadbeigi, Y.; Tabrizchi, M. Ion Mobility Spectrometry of Heavy Metals. Anal. Chem. 2016, 88 (14), 7324-7328. https://doi.org/10.1021/acs.analchem.6b01664.

(22) Dion, H. M.; Ackerman, L. K.; Hill, H. H. Detection of Inorganic lons from Water by Electrospray Ionization-Ion Mobility Spectrometry. Talanta 2002, 57 (6), 1161-1171. https://doi.org/10.1016/S0039-9140(02)00197-2.

(23) Crawford, C. L.; Fugate, G. A.; Cable-Dunlap, P. R.; Wall, N. A.; Siems, W. F.; Hill, H. H. The Novel Analysis of Uranyl Compounds by Electrospray-Ion Mobility-Mass Spectrometry. International Journal of Mass Spectrometry 2013, 333, 21-26. https://doi.org/10.1016/j.ijms.2012.08.004.

(24) Davis, A. L.; Clowers, B. H. Stabilization of Gas-Phase Uranyl Complexes Enables Rapid Speciation Using Electrospray Ionization and Ion Mobility-Mass Spectrometry. Talanta 2018, 176, 140-150. https://doi.org/10.1016/j.talanta.2017.07.090.

(25) Eiceman, G. A.; Karpas, Z.; Jr, H. H. H. Ion Mobility Spectrometry, Third Edition; CRC Press, 2013.

(26) Mason, E. A.; McDaniel, E. W. Transport Properties of Ions in Gases. NASA STI/Recon Technical Report A 1988, 89.

(27) Schneider, B. B.; Nazarov, E. G.; Londry, F.; Vouros, P.; Covey, T. R. Differential Mobility Spectrometry/Mass Spectrometry History, Theory, Design Optimization, Simulations, and Applications. Mass Spec Rev 2015, n/a-n/a. https://doi.org/10.1002/mas.21453.

(28) Mason, E. A.; McDaniel, E. W. Transport Properties of lons in Gases. Wiley-Interscience 1988, 89, 576.

(29) Shvartsburg, A. A. Differential Ion Mobility Spectrometry: Nonlinear Ion Transport and Fundamentals of FAIMS; CRC Press, 2008.

(30) Bowers, M. T.; Kemper, P. R.; von Helden, G.; Koppen, P. A. M. van. Gas-Phase lon Chromatography: Transition Metal State Selection and Carbon Cluster Formation. Science 1993, 260 (5113), 1446-1451.

(31) Clemmer, D. E.; Jarrold, M. F. Ion Mobility Measurements and Their Applications to Clusters and Biomolecules. Journal of Mass Spectrometry 1997, 32 (6), 577-592.

(32) Campbell, J. L.; Zhu, M.; Hopkins, W. S. Ion-Molecule Clustering in Differential Mobility Spectrometry: Lessons Learned from Tetraalkylammonium Cations and Their Isomers. Journal of The American Society for Mass Spectrometry 2014, 25 (9), 1583-1591. https://doi.org/10.1007/s13361-014-0939-3.

(33) Buryakov, I. A.; Krylov, E. V.; Nazarov, E. G.; Rasulev, U. Kh. A New Method of Separation of MultiAtomic lons by Mobility at Atmospheric Pressure Using a High-Frequency Amplitude-Asymmetric Strong Electric Field. International Journal of Mass Spectrometry and Ion Processes 1993, 128 (3), 143-148. https://doi.org/10.1016/0168-1176(93)87062-W.

(34) Hall, A. B.; Coy, S. L.; Nazarov, E. G.; Vouros, P. Rapid Separation and Characterization of Cocaine and Cocaine Cutting Agents by Differential Mobility Spectrometry-Mass Spectrometry. Journal of Forensic Sciences 2012, 57 (3), 750-756. https://doi.org/10.1111/j.1556-4029.2011.02033.x.

(35) Ayodeji, I. Rapid Pre-Filtering of Amphetamine and Derivatives by Direct Analysis in Real Time (DART)-Differential Mobility Spectrometry (DMS). UK 20170914, 9 (34), 5044-5051. https://doi.org/10.1039/c7ay00892a.

(36) Harper, J. D.; Charipar, N. A.; Mulligan, C. C.; Zhang, X.; Cooks, R. G.; Ouyang, Z. Low-Temperature Plasma Probe for Ambient Desorption Ionization. Anal. Chem. 2008, 80 (23), 9097-9104. https://doi.org/10.1021/ac801641a. 
(37) Feider, C. L.; Elizondo, N.; Eberlin, L. S. Ambient Ionization and FAIMS Mass Spectrometry for Enhanced Imaging of Multiply Charged Molecular lons in Biological Tissues. Analytical Chemistry 2016, 88 (23), 11533-11541. https://doi.org/10.1021/acs.analchem.6b02798.

(38) Cooper, H. J. To What Extent Is FAIMS Beneficial in the Analysis of Proteins? J Am Soc Mass Spectrom 2016, 27, 566-577. https://doi.org/10.1007/s13361-015-1326-4.

(39) Sinatra, F. L.; Wu, T.; Manolakos, S.; Wang, J.; Evans-Nguyen, T. G. Differential Mobility Spectrometry-Mass Spectrometry for Atomic Analysis. Anal. Chem. 2015, 87 (3), 1685-1693. https://doi.org/10.1021/ac503466s.

(40) Manolakos, S.; Sinatra, F.; Albers, L.; Hufford, K.; Alberti, J.; Nazarov, E.; Evans-Nguyen, T. Differential Mobility Spectrometry for Inorganic Filtration in Nuclear Forensics. Analytical Chemistry 2016, 88 (23), 11399-11405. https://doi.org/10.1021/acs.analchem.6b01441.

(41) Ayodeji, I.; Vazquez, T.; Song, L.; Donovan, J.; Evans-Nguyen, T.; Badal, S. P.; MacLean, G. M.; Shelley, J. T. Coupling Flowing Atmospheric Pressure Afterglow (FAPA) with Differential Mobility Spectrometry-Mass Spectrometry (DMS-MS) for Rapid Analysis of Solid Metal Complexes. International Journal of Mass Spectrometry 2019, 438, 157-165.

(42) Schneider, B. B.; Covey, T. R.; Coy, S. L.; Krylov, E. V.; Nazarov, E. G. Planar Differential Mobility Spectrometer as a Pre-Filter for Atmospheric Pressure Ionization Mass Spectrometry. International Journal of Mass Spectrometry 2010, 298 (1-3), 45-54. https://doi.org/10.1016/j.ijms.2010.01.006.

(43) Ayodeji, I.; Vazquez, T.; Bailey, R.; Evans-Nguyen, T. Rapid Pre-Filtering of Amphetamine and Derivatives by Direct Analysis in Real Time (DART)-Differential Mobility Spectrometry (DMS). Anal. Methods 2017. https://doi.org/10.1039/C7AY00892A.

(44) Krylov, E.; Nazarov, E. G.; Miller, R. A.; Tadjikov, B.; Eiceman, G. A. Field Dependence of Mobilities for Gas-Phase-Protonated Monomers and Proton-Bound Dimers of Ketones by Planar Field Asymmetric Waveform Ion Mobility Spectrometer (PFAIMS). J. Phys. Chem. A 2002, 106 (22), 5437-5444. https://doi.org/10.1021/jp020009i.

(45) McDonald, L. W.; Campbell, J. A.; Clark, S. B. Failure of ESI Spectra to Represent Metal-Complex Solution Composition: A Study of Lanthanide-Carboxylate Complexes. Anal. Chem. 2014, 86 (2), 1023-1029. https://doi.org/10.1021/ac401751r.

(46) Agnes, G. R.; Horlick, G. Electrospray Mass Spectrometry as a Technique for Elemental Analysis: Preliminary Results. App/ Spectrosc 1992, 46 (3), 401-406. https://doi.org/10.1366/0003702924125311.

(47) Schneider, B. B.; Covey, T. R.; Coy, S. L.; Krylov, E. V.; Nazarov, E. G. Planar Differential Mobility Spectrometer as a Pre-Filter for Atmospheric Pressure Ionization Mass Spectrometry. International Journal of Mass Spectrometry 2010, 298 (1-3), 45-54. https://doi.org/10.1016/j.ijms.2010.01.006.

(48) Schneider, B. B.; Londry, F.; Nazarov, E. G.; Kang, Y.; Covey, T. R. Maximizing Ion Transmission in Differential Mobility Spectrometry. Journal of The American Society for Mass Spectrometry 2017, 28 (10), 2151-2159. https://doi.org/10.1007/s13361-017-1727-7.

(49) Uechi, G. T.; Dunbar, R. C. Space Charge Effects on Relative Peak Heights in Fourier Transform-Ion Cyclotron Resonance Spectra. J Am Soc Mass Spectrom 1992, 3 (7), 734-741. https://doi.org/10.1016/1044-0305(92)87086-E.

(50) Hoegg, E. D.; Manard, B. T.; Wylie, E. M.; Mathew, K. J.; Ottenfeld, C. F.; Marcus, R. K. Initial Benchmarking of the Liquid Sampling-Atmospheric Pressure Glow Discharge-Orbitrap System Against Traditional Atomic Mass Spectrometry Techniques for Nuclear Applications. J. Am. Soc. Mass Spectrom. 2019, 30 (2), 278-288. https://doi.org/10.1007/s13361-018-2071-2.

(51) Ayodeji, I.; Vazquez, T.; Song, L.; Bailey, R.; Donovan, J.; Evans-Nguyen, T.; Shelley, J. T. Coupling of Flowing Atmospheric Pressure Afterglow and Differential Mobility Separation toward Fieldable 
Post-Detonation Debris Analysis by Mass Spectrometry. In The 11th Harsh-Environment Mass Spectrometry Workshop; Poster and talk: Oxnard, CA, 2017.

Digital Abstract

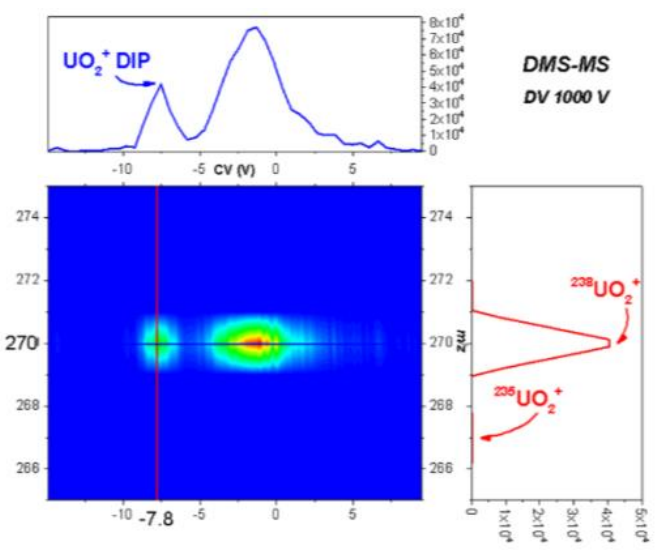

